\title{
Erratum: Effort and reward imbalance factors motivating Namibian professional nurses to participate in continuous professional development: A confirmatory factor analysis
}

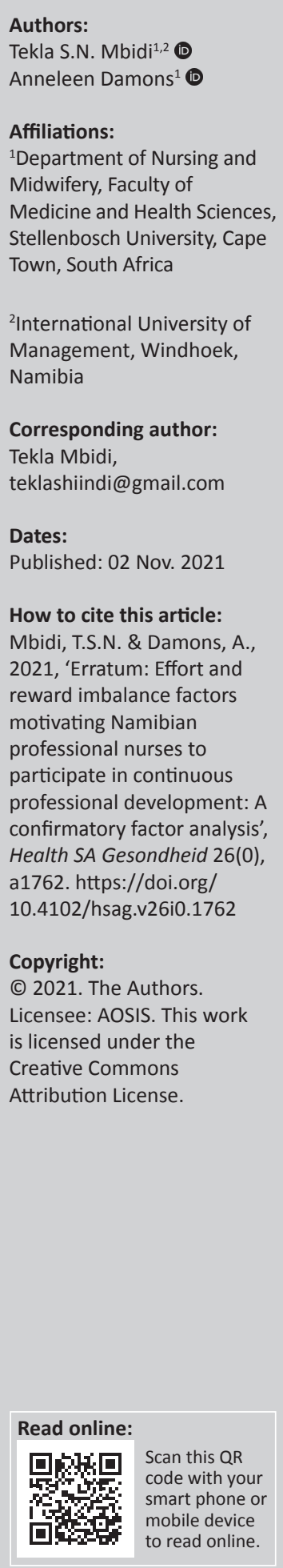

Affiliations:

Department of Nursing and

Stellenbosch University, Cape

${ }^{2}$ International University of

Management, Windhoek,

Corresponding author:

Tekla Mbidi,

Dates:

Published: 02 Nov. 2021

w to cite this article:

2021, 'Erratum: Effort and reward imbalance factors motivating Namibian professional nurses to professional development: $A$ confirmatory factor analysis' Health SA Gesondheid 26(0), a1762. https://doi.org/

\section{Copyright:}

(C) 2021. The Authors Licensee: AOSIS. This work

Creative Commons

Attribution License.
In the version of this article initially published, Mbidi, T.S.N. \& Damons, A., 2020, 'Effort and reward imbalance factors motivating Namibian professional nurses to participate in continuous professional development: A confirmatory factor analysis', Health SA Gesondheid 25(0), a1313. https:/ / doi.org/10.4102/hsag.v25i0.1313, the second author's affiliation was given incorrectly in the 'Affiliation' section. The correct affiliation should be 'Department of Nursing and Midwifery, Faculty of Medicine and Health Sciences, Stellenbosch University, Cape Town, South Africa' instead of 'International University of Management, Windhoek, Namibia'.

This correction does not alter the study's findings of significance or overall interpretation of the study's results. The publisher apologises for any inconvenience caused. 